\title{
ETHICAL CONCERNS AND CONTRIBUTIONS IN RESPONSE TO CLIMATE CHANGE AND THE LINKS TO WELL-BEING: A STUDY OF UNIVERSITY STUDENTS IN THE NETHERLANDS
}

\author{
Mona Betour El Zoghbi', Walid El Ansari² \\ ${ }^{1}$ General Contracting and Quarries Corporation (GCQC), Zgharta, Lebanon \\ ${ }^{2}$ Faculty of Applied Sciences, University of Gloucestershire, Gloucester, United Kingdom
}

\begin{abstract}
SUMMARY
Aims: This study explored the concerns and contributions of university students in response to the ethical dimensions of climate change, and the implications for their well-being. The study focused on university students as leaders of future society while facing complex environmental and socio-economic challenges.

Methods: A total of 8 focus groups (FG) were conducted (66 participants from over 10 different universities across the Netherlands). In addition, 9 in-depth interviews with Dutch university students from different academic backgrounds, and 16 interviews with Dutch key informants in the environment, youth and public health fields were undertaken. The first author also attended (as participant-observer) three major events themed around youth and environmental issues across different regions in the Netherlands.

Results: University students in the Netherlands are mostly concerned about the increasing social and economic inequalities between the global North and South, and the implications for impoverished and uneducated communities. Participants raised concerns over the transfer of materialistic value systems and unsustainable practices from developed to developing countries. The participants' main contributions in response to climate change were largely driven by feelings of guilt and responsibility, an ecological worldview, and desire to play a positive role in society.

Conclusion: Establishing formal youth platforms across academic, civic and political institutions could provide legitimate and empowering opportunities for university students to participate in consultations and debates of future environmental policies and development strategies. Such platforms could enhance the agency and well-being of university students for addressing their concerns over existing climate inequalities and other ethical dilemmas.
\end{abstract}

Key words: youth, climate change, ethics, equity, emotions, culture

Address for correspondence: M. Betour El Zoghbi, General Contracting and Quarries Corporation (GCQC), Zgharta Main Road, Zgharta, JA Bldg., Lebanon. E-mail: monazoghbi@gmail.com

\section{INTRODUCTION}

Climate change presents a pressing ethical concern which accentuates existing global health and security inequalities, and touches on intra and inter-generational facets of inequity (1). It poses moral questions across the global North and South and across generations regarding the responsibility for green-house gas emissions, inequalities in vulnerability and adaptation, and unsustainable use of natural resources for development (2). In general, countries most vulnerable to climate change are also the poorest, often suffering from a myriad of challenges such as prevalence of poverty and disease, political instability, poor governance, and weak economies (3).

As climate change poses long-term challenges, youth are one of the main population groups who are threatened by the climate risks continuously over their lives. The long-term risks from climate change may threaten young people's physical, emotional and mental health, disrupt their livelihoods and social relationships, and challenge their lifestyles and job prospects. These multiple challenges can adversely influence youth health and well-being
(4). First, young people's physical and mental health can be threatened by the consequences of extreme weather events and natural disasters, and the ensuing rise in infectious diseases, food and water shortages, and intense temperature fluctuations (5). Second, climate change can instill fear or mental worry amongst young people who are concerned with its impacts in their future and unable to adapt or otherwise protect themselves. Third, climate change threatens to trigger social and political instability over natural resources and forced migration to safer locations, all of which can significantly debilitate young people's health, livelihoods and social cohesion (6).

The challenges posed by climate change can be particularly taxing to university students who constitute the future leaders and decision-makers of society. The ensuing variations in lifestyle and patterns of employment as a result of climate change can overburden university students with additional emotional and mental pressures to succeed in their lives and jobs. Concern over future risks has been found to generate emotional and social distress, and the lack of adequate and stable employment can adversely impact on young people's physical, mental and emotional health, 
social cohesion and sense of autonomy (7). Nevertheless, such challenges to youth, especially university students, will vary considerably depending on their geographic location and personal and institutional resilience.

The complexity of the ethical dimensions of climate change which challenge university students' long-term well-being signify the importance of more in-depth understandings of the ethics and climate change as perceived and experienced by university students in different countries. Yet the focus of the current literature on the ethics of climate change has generally been on the philosophical debates about the moral imperatives for addressing the rights and responsibilities of various stakeholders (8). Less research and debate exists about the concerns and obligations of individuals within different population groups, and across diverse socio-economic and country contexts (9).

This mismatch between the emphasis in current literature on the importance of the multi-faceted ethical dimensions of climate change vis-à-vis the less explored individual and contextual interpretations of such dimensions manifests the need for qualitative studies that explore these themes in-depth with particular population groups. Given that university students constitute key players within the current and future fight against climate change, it is important to explore the ways in which their beliefs and concerns about climate change, including whether or not it poses a moral imperative, shape their responses and actions to this global problem.

We sought to explore in-depth the concerns of university students to the ethical dilemmas on climate change, and how they respond to such concerns in their actions in their personal and professional lives. The study was conducted among university students in the Netherlands in order to provide valuable insights into the perspectives and experiences of the current and future stakeholders of a society that, being European, has contributed in part to the ethical challenges created by the global climate change crisis. This study incorporates a holistic and multi-dimensional perspective regarding well-being, seeking to explore the implications of climate change at multiple levels including: a) personal feelings (such as physical, emotional and mental health); b) personal perspectives (such as hopes and beliefs, future visions, sense of security, and perceived control); and, c) personal and social functioning (with regards to their capacities, social relations, academic and professional functioning, self-efficacy and agency).

We explored the concerns and contributions of university students from an ethical perspective towards the global climate change crisis. The study aimed to enhance understanding of the students' main ethical concerns, and the ways in which they respond to such concerns with action and contributions to society. We explored the personal experiences of university students from different demographic and academic backgrounds to present a diverse yet profound picture on their concerns and contributions at a personal level. The specific objectives were to:

- explore students' main concerns of the ethical implications of climate change;

- explore the personal contributions that students undertake in response to such ethical concerns;

- discuss the implications of such concerns and contributions for the well-being of university students with regards to climate change;
- provide recommendations on strategies to enhance the wellbeing of university students regarding the ethical dimensions of climate change.

\section{MATERIALS AND METHODS}

This qualitative study was undertaken from a critical interpretivist research approach to generate in-depth and contextual data with a diversity of students across universities in the Netherlands. Methodologically, the study emphasized the importance of social interactions and dialogue for gaining insight into the participants concerns and contributions (10). The study also sought to enhance the understanding of the environmental, socio-cultural, academic and political setting in the Netherlands with regards to the research themes. The study population consisted of Dutch university students aged 18-30, both undergraduates and graduates, from different socio-demographic and academic backgrounds, enrolled at evarious universities across different regions of the Netherlands.

\section{Data Collection}

The study was approved by the Research Ethics Committee of the University of Gloucestershire, United Kingdom. The fieldwork for this study was undertaken across three months of 2011 as the first author visited different regions of the Netherlands for data collection. A variety of qualitative research methods were employed in order to achieve in-depth and contextual understanding of the research themes (10).

We used focus groups to achieve a rich dialogic setting where key themes could be explored amongst diverse participants (11). We conducted 8 focus groups (FG) comprising 66 participants from 12 universities located in different areas including Amsterdam, Hague, Utrecht, Rotterdam, Wageningen, Maastricht, and Arnhem. In addition, 9 in-depth interviews were undertaken with Dutch university students from different academic backgrounds (e.g., Environmental Sciences, Law, Economics, Engineering, Social Sciences, Medicine) to further explore their personal experiences and concerns. We also conducted 16 interviews with key informants engaged in the environment, youth and/or public health fields in the Netherlands in order to attain a wider understanding of the country setting. Moreover, the first author attended 3 national events as participant-observer (a reunion by a youth nature group; an on-campus workshop by a student sustainability committee; and a youth-run energy efficiency campaign). Finally, the author kept a reflective research diary to detail the developments of the research process and fieldwork (11). The criteria for inclusion in the study were intentionally kept minimal and included that participants needed to be Dutch university students, preferably from different academic disciplines, aged 18-30, undergraduates and graduates, and both males and females.

\section{Thematic Data Analysis}

We applied thematic analysis using an inductive analytical approach through identifying key themes, patterns and meanings from the data (11). We generated the main codes and categories from the data itself rather than from pre-assigned categories, which meets the study's objectives for understanding the partici- 
pants' experiences from their own viewpoints and the particularity of the research context.

The data analysis was conducted through three phases. The first phase comprised transcribing the data verbatim and preliminary data reading and examination. The second phase entailed categorization of the data into recurring themes to explore emerging themes and establish preface relationships between these themes. In the third phase we applied theoretical coding to examine indepth broad categories, identify connections across different themes, and relate these themes to their particular setting (11).

Research ethics were maintained by ensuring privacy, confidentiality, anonymity, and safe storage of data (10). Participants also read and signed an information sheet and completed and signed an ethical consent form.

We maintained rigor through applying several validation techniques. The first validation technique was triangulation of findings emerging from the different data collection methods. We substantiated evidence from different data sources to overcome problems related to bias, through using different data collection methods (e.g. focus groups, interviews and participant-observation). The second technique to enhance rigor was prolonged engagement in the field and thick and detailed descriptions of the research process. This helped develop in-depth understanding of the research issues in the particular context of the Netherlands which can enhance the understanding and interpretation of the generated data. The third validation technique was researcher reflexivity to critically reflect upon the researchers' role in influencing the data generation and analysis process through our prior assumptions or understandings of the research themes (10).

\section{DISCUSSION}

The findings are presented in two main categories covering our participants' concerns and contributions regarding the ethical dimensions of climate change. Fig. 1 summarizes the key themes and sub-themes which are further discussed in the below sections. The first three themes presented in Fig. 1 addressed objective one of the study (participants' ethical concerns about climate

\begin{tabular}{|c|c|}
\hline $\begin{array}{l}\text { Ethical Concerns over } \\
\text { Global Inequalities }\end{array}$ & $\begin{array}{l}\text { - Concerns over inequalities in impacts of } \\
\text { climate change } \\
\text { - Concerns over inequalities in adaptation } \\
\text { mechanisms }\end{array}$ \\
\hline $\begin{array}{l}\text { Ethical Concerns over } \\
\text { National Inequalities }\end{array}$ & $\begin{array}{l}\text { - Concerns over the unemployed and } \\
\text { uneducated }\end{array}$ \\
\hline $\begin{array}{c}\text { Ethical Concerns over } \\
\text { Materialistic Value } \\
\text { System }\end{array}$ & $\begin{array}{l}\text { - Concerns over transfer of materialistic } \\
\text { social value systems from North to } \\
\text { South } \\
\text { - Concerns over challenges of changing } \\
\text { values and worldviews }\end{array}$ \\
\hline $\begin{array}{l}\text { Ethical Contributions } \\
\text { in Response to } \\
\text { Climate Change }\end{array}$ & $\begin{array}{l}\text { - Contributions driven by feelings of guilt } \\
\text { and responsibility } \\
\text { - Contributions driven by an ecological } \\
\text { worldview } \\
\text { - Contributions driven by desire to play a } \\
\text { positive role in society }\end{array}$ \\
\hline
\end{tabular}

Fig. 1. Concerns and contributions in response to climate change: findings across universities in the Netherlands. change). The fourth theme addressed objective two of the study (participants' contributions in response to climate change). The subsequent discussions that follow these findings across the different themes addressed objective three of the study in terms of the implications for well-being. Finally, the concluding section in this article addressed objective four of the study (the implications of the students' concerns and contributions for their well-being).

\section{Theme 1: Ethical Concerns over Global Inequalities}

Data from our sample highlighted a shared concern amongst the participants regarding the social and ethical dimensions of climate change. This recurrent theme surfaced in almost every data collection session, and participants perceived climate change as an issue of global inequality.

\section{Concerns over Inequalities in Impacts of Climate Change}

The majority of participants considered themselves to be safe against the potential impacts of climate change, associating their lack of vulnerability with their perceptions of financial security. Two points were recurrent: the first point was participants' concern over the widening gap between the rich and poor; the second point was their discussion of the increase in political conflicts and climate-induced migration.

First, our participants raised concern over the widening gaps between the rich, whom they considered to be safe from climate change, and the poor whom they viewed as the disempowered victims. For example, two FG participants expressed their lack of concern of from climate change to their own lives and greater concern for the poor: "It hardly affects you. We have money to buy crops from other parts of the world. It's the poor people who will be affected but us. No, I don't feel personally threatened by climate change. We have tools and money to combat that, not a problem for Netherlands. But a major issue for other countries who do not have these resources. In worst case scenario, I could move to another place and we are highly educated and can survive elsewhere...Personally I'll be fine but I'm concerned about other people who will die."

Another FG participant expressed her lack of concern over the health risks from climate change due to her geographic location and financial security. She voiced feelings of guilt of existing inequalities in the health implications from climate change for poor communities: "I'm not worried from climate change concerning my health at all, because I live here, I'm the lucky one, I can buy my own food and eat what I want. I feel guilty that we are living here and we are safe and other part of world is suffering... Why would I be worried about my own health, that's little egocentric, selfish."

A Dutch participant interviewed at a youth sustainability event in Amsterdam considered it a luxury to have access to information and solutions when compared to the challenges faced by citizens in developing countries: "We have access to information, we have chance to think about solutions. They don't because they have other problems. We have the luxury to contemplate about it... I recently saw in a magazine title was: Europe takes everything from Africa but we don't give anything back."

Several participants also expressed ethical concerns in their personal visions in which they described the social inequities that 
they imagine taking place in a climate-threatened future. One FG participant described the social and economic divisions that would take place in future society as a result of climate change impacts: "The green hill where rich and secure communities would live and a big line separating in the middle of the world as the poor are left to face the climate challenges alone, because rich people in safe side don't want to see the other side, don't want to see the problems. Division between these 2 groups of people. In my head there's always a green hill, and I'm imagining 20-30 years, I would be either on good side or going to green hill because I'm very bitter and this would be place where I could escape to."

Many participants' future visions also showed concern over future livelihood implications for poor communities. They expressed worry about the increasing financial disparities in a climate-threatened future, and the consequences of forced migration and the creation of climate refugees, as expressed by two FG participants: "I'm pessimistic about the future in poor countries. I see lots of possible conflicts triggered by climate change because natural resources are limited and exhaustible cannot be regenerated...lots of conflicts between countries using shared resources. If people can't feed their children or resource war or energy crisis or environmental disaster, they will be forced into migration. Where would these people go...We said we would take refugees but now we don't want even people from Eastern Europe to come to our country.'

One FG participant questioned the speed of governmental intervention for responding to the risks of climate change, and considered that future vulnerabilities would be increasingly shaped by financial security: "Governments, not just national but UN, will be super later with interventions. I see 2 sides: one surviving, the other surviving but not so well so I drew Africa. Lots of island victims of climate change, and picture of rich man with suitcase filled with money. People on bad side are because they don't have enough money to move to safer places. The good place is coincidence, because it's where you're born. So we are in Holland, having it relatively good."

The recurrent expression of concern over social and ethical implications of climate change by our study participants is consistent with findings of other research $(12,13)$. Norgaard discussed the denial and emotional responses to climate change, indicating that "some of the reasons for ignoring an issue are related to awareness of one's privileged position in the global economic order. Troubling emotions are troubling due to social context." (14). Similarly, Maibach et al. studied and analyzed audience categories on climate change information to find lower perceptions of risk to climate change amongst people who are educated and of relatively high socio-economic status (15). Such insights are congruent with our findings, as our participants were university students who generally have better opportunities for education, learning and employment than their general peers, and could therefore feel more empowered professionally and financially to manage the climate risks.

Nevertheless, according to the American Psychological Association, even in the absence of direct impact or personal experience, mental health might be threatened by the perception and fear of climate change (16). Feelings of worry, guilt or despair over climate change can adversely impact subjective well-being, as young people may experience mental and emotional distress if they struggle to secure adequate sources of income while facing uncontrollable environmental risks. The uncertainty of climate impacts and scope and of future implications can generate feelings of loss of security or control over the future, yet the implications of such negative emotions are less understood because of a lack of recognition of subjective feelings of environmental loss in traditional scientific and economic frameworks (17).

\section{Concerns over Inequalities in Adaptation Mechanisms}

Several participants considered that the adaptation mechanisms undertaken in developed countries might exert additional pressure and degradation on the natural environment in developing countries and increase global inequalities in climate change response mechanisms. An FG participant expressed such concerns: 'I'm afraid that adaptation in Western countries will automatically have big effect on developing countries due to the fact that we need to produce a lot of energy. Might be economically feasible to buy biomass or exchange emissions with developing countries and then they have much less to become sustainable themselves. I'm more afraid about that than about climate change risks. I'm afraid that sustainability for governments and politicians is about green energy only and not looking into North-South relations."

One interviewee also raised similar concerns over what he described as the externalization of the pollution chain: "Developed countries like Netherlands are externalizing the pollution chain. They take their productions and emissions to third world countries, but do not help to develop such communities and economies."

Another FG participant's ethical concerns revolved mainly around the implications of capitalist governance systems on future decisions for adaptation to climate change: "As we see in America, capitalism will be more important. If a big area floods, government will ask is it worth money-wise to fix it or better to leave it and people have to find an other place. Already you see this in America happening now. This worries me."

Only a few of our participants were concerned about impacts on their personal lives or health, which is congruent with findings by other studies $(18,19)$. A review of in-depth studies across the world on the individual understandings and perceptions of climate change concluded that: "individuals'perceptions about climate change are linked to equity, development, and perceived economic power, where socio-political context and the connection between management and science play an important role in risk perception." (13). The findings in our study in terms of participants' concerns over the global moral implications of climate change similarly reveal the influence of financial security, geographic location and socio-political power dynamics across countries in the global North and South on their perceived risk from its impacts.

\section{Theme 2: Ethical Concerns over National Inequalities}

Numerous participants who considered themselves safe from the impacts of climate change due to their financial security and high educational attainment, raised concern over potential implications for Dutch citizens who are un-educated and unemployed. One FG participant indicated that: "Maybe for us as elite Dutch we will be OK. But the average Dutch person might not be able to afford growing food prices." 
In another FG, participants discussed different levels of security and fulfillment based on provision of basic needs: "In our discussion, we talked about Maslow pyramid, we are all in the top, and its about self-fulfillment, so we can think about it it's a luxury, but they are in lower level so they have to think about their food and their living. When looking at non-elite, they have other stuff to worry about. Livelihoods and security and health and rent. They don't have time to worry about this."

Furthermore, some participants indicated the importance of governance systems that take into account existing socioeconomic inequalities in the Dutch society and the need for taxations and other climate-targeted policies to consider such inequalities: "Government should subsidize more according to socio-economic background. Depending on amount of income each household gets, they task according to that. So rich can afford getting their own solar panels but poor maybe government can subsidize. Government should take role in making it equal rather than based on economic background; should standardize sustainability programmes, has to involve everyone, not just rich side of society."

The need for government subsidies and progressive tasks was also highlighted by several of our key informants who stressed the importance of mainstreaming sustainability in government policies. Our findings reflect the greater need for addressing our participants' concerns of global and national inequalities of climate change in national and international governmental negotiations and policies, and for consulting university students on such policies. Studies have shown improved mental health and well-being amongst young people who have been provided with opportunities to participate in civic and environmental decision-making (20).

\section{Theme 3: Ethical Concerns over Materialistic Social Value Systems}

\section{Concerns over Transfer of Western Lifestyle to Deve- loping Countries}

Several participants were concerned over the influence of current Western value systems and lifestyles on similar implications for poor countries. They blamed the materialistic and highly consumptive practices of Western communities for contributing to changes in the climate system and the ensuing challenges for global society. One FG participant felt that: "Most of developing countries want to have this lifestyle of developed countries, through marketing and communication, saying that this way of living makes you happier. It's a difficult shift in people's minds. It's not that they need to have more cars or live in bigger houses to be happier, they can still do different things and still have a better life."

Other FG participants contemplated the difficulty of asking poor communities to live more sustainable lifestyles: "Do you expect the average Indian to say I won't buy a car coz of climate change? No. They would say why should the American and the European have 2 cars? 2 TVs? It comes from us. We are telling them you can't have what we have had for years. Poor countries arguing now it's our turn to develop. It's understandable, we influenced that. Maybe we should set a good example for them. But then again for them it's the western world imposing on them."
The literature suggests that people's practices and behaviours are embedded in social and institutional contexts and cultural norms, and scholars are increasingly emphasizing the need for fundamental societal transformations towards sustainable modes of production and consumption (21). In agreement with such sentiments, our participants emphasized the role of different stakeholders in driving such new modes of thinking, valuing and living, which highlights their understanding of the importance of partnerships for facilitating the transition to a more secure and sustainable society.

\section{Concerns over the Challenge of Transforming Social Values towards Sustainability}

Many participants criticized current materialistic cultural systems which promote individualistic and unsustainable lifestyles. One FG participant blamed the current materialistic value systems for rising global inequalities: "Worst thing now is value system, that's what needs to be changed from the beginning. Because there's a lot of achievement in relation to resources you have; the richer you are the more successful you are; that's why you have such unequal distribution of resources, because if you associate your own self worth with resources you own and money you make, for sure you want to make as much money as possible."

Another FG participant emphasized the need for reshaping society through adequate education and governance systems which promote more compassionate worldviews and environmentalfriendly behaviours: "Need to realize we are all interconnected, we can't be individualistic anymore in the way we live our lives. Need to think in a community feeling; otherwise most people won't be sustainable. When people buy a car they don't think of kids in Africa. They don't think of how much energy and resources they waste. Up to now it was not necessary because there was enough for Europe and America and now not sufficient resources when poor countries need to develop. We need to see the bigger picture."

The role of educational institutions in vitalizing this shift in paradigms and practices is being increasingly emphasized. Scholars have suggested that current education still promotes unsustainable practices, and have argued for embedding education for sustainability in higher education to promote more reflective, critical and holistic worldviews and sustainable practices (22).

\section{Theme 4: Ethical Contributions in Response to Cli- mate Change}

The study captured important findings regarding the main contributions that participants make in response to their ethical concerns from climate change. Such contributions were mainly driven by participants' feelings of guilt and responsibility, their understandings of the interconnection between their lives and wider ecosystem, and by their desire to contribute positively to society.

\section{Contributions Driven by Feelings of Guilt and Re- sponsibility}

Participants often related their motivation for environmental work with feelings of guilt and responsibility for the adverse impacts on developing countries, as indicated by this FG participant: "There's a difference between being scared and feeling 
responsible. Because we feel responsible for it, it feels bad, but I'm not scared from its consequences."

One participant in a youth sustainability workshop cited ethics as a main motivation for his decision to undertake internship at a sustainability organization: "I had the chance to be at Philips or Nike but I chose this sustainability organization. That was my decision, because I knew Nike has sweatshops in Vietnam, so I thought I could do my part by volunteering here."

A student interviewee shared similar perspectives regarding her ethical choices for employment: "Since I will be in a management position in few years, climate change will affect my job. I will have to consider the environment in my decision. I feel responsible when looking for jobs I look at how green an organization is. I don't want to work for Shell for example. It's horrible the way they pollute and don't take responsibility to clean it."

Research has shown that people become more stressed and more vulnerable to stress-related illnesses if they feel they have little control over the causes of stress, its duration and intensity, or if they consider the stress will debilitate their personal circumstances (7). Therefore, the availability of forums and pathways that can empower young people to actively participate in devising and applying positive societal changes is critical for enhancing their well-being. The sense of control over one's environment and life and the ability to participate in policy-making are central functional capabilities that can enhance well-being (6)

\section{Contributions Driven by an Ecological Worldview}

Many participants expressed motivation for contributing to change driven by their understandings of the interconnections across the ecosystem. An FG participant linked environmental problems such as climate change with wider economic and political systems that she considered to be unethical: "If we are going on like now, I really see this happening. Now it's with oil and then with food. I already see it, with rich countries going into other countries and stealing their resources, like Afghanistan and Iraq, and all products we buy from Africa, rich people get all the food and no food left for people who live there. That's why I'm angry and doing so much for the environment, because it's not only the environment, it's the fact that people have more power over others and over animals."

Another FG participant discussed modes of global consumption and production, and the influence of the consumer on the livelihoods of impoverished communities in developing countries: "I saw in documentary a local farmer in Peru: You pay with your wallet so you decide what's in supermarket...I try to buy biological meat rather than not eat meat at all, so it would be more demand in the market rather than no demand for it."

A number of university students from our sample pointed to the role of their upbringing and surrounding physical environment in influencing their understandings and enthusiasm for environmental work. An FG participant discussed the impact of her upbringing in instilling feelings of responsibility to contribute to society: "For me personally, I have been brought up from my parents to care about nature, and then when you see things you were brought to care about being destroyed, that's when you fight. So now I'm volunteering as an activist with this international environmental organization...It's my feeling of responsibility, as a world citizen. We are living in Holland and we don't have to worry about our health or future because government will find solution before we drown. So it's about me wanting to be connected to that other side of the world, to the less fortunate."

The literature highlights the role of parenting in establishing pro-environmental values, and the influence of formative experiences in nature and youth groups in promoting environmentalfriendly actions (20). Our findings support such sentiments as our participants discussed the role of upbringing and nature experiences in instilling a sense of responsibility and efficacy for environmental protection and sustainable practices.

\section{Contributions Driven by Desire to Play a Positive Role in Society}

Some FG participants described their individual contributions to sustainability to be driven by their desire to raise public awareness: "I wanted to do something that would make me feel like I contributed to society, and especially the environment because people just don't know. So how could you raise that awareness and actually try to change something and go home with a feeling that you tried to make a change, and that u actually can make a change. That's how I got involved... Mainly to feel like I make a contribution. I make conscious decision to eat biological meat. If I only buy meat 2 days per week then even if more expensive I buy biological meat to support the biological farmers instead of not buying any meat...."

An interviewee also discussed the small role she could play as a consumer in influencing more ethical practices in agricultural production: "I'm into local food. Good to promote them; make it happen that farmers sell their own products, instead of selling to supermarket and all that process. Buy directly from farmer: people associate with what they are buying and know its value and farmers get good price."

These findings demonstrate the personal actions that many of our study participants were undertaking in their desire to contribute positively to raising public awareness and action on climate change. Such actions can enhance their emotional health and reduce their mental worry and stress over future climate risks. The literature suggests several positive contributors to personal well-being including feeling engaged in meaningful and challenging activities, having career goals and being able to work towards them, and having a meaningful and manageable perspective of one's life and surrounding environment (23).

The salience of our study findings is that they were captured through the perspectives and interactions of university students themselves, as opposed to common methods of surveys or expert reviews used in other studies. The findings provide novel insights into how youth think and act about the ethical dimensions of climate change. However, the study has limitations. First, the voluntary nature of participation in focus groups and interviews presents uncontrollable limitations to the size of the data collection sessions and the number and profile of participants who took part in the study. Second, the data generated with these participants is context-specific and participant-specific and the findings cannot be generalized across all university students in the Netherlands. Nevertheless, our aim with this research was not to build theory and generalize findings, but rather to explore in-depth the personal experiences of a wide diversity of university students in the Netherlands. 


\section{CONCLUSIONS}

The findings of the present study suggest that university students' moral concerns and contributions with regards to climate change can have various implications for their short and longterm well-being. The provision of diverse opportunities for the participation, education and leadership of university students on this global issue can empower them to contribute to positive societal change and enhance their sense of well-being in managing future risks to their health and livelihoods. Further, the generated insights could also be relevant to university students in other European contexts whose countries and societies have had similar development pathways which contributed partly to the global climate change crisis, and are now faced with the ethical dilemmas of climate change.

Based on the in-depth and contextual data generated, we propose the following recommendations for key stakeholder groups. Academic institutions could incorporate education for sustainability, ethics education and critical thinking skills to equip students with knowledge and skills for future employability. This is important as most participants associated their vulnerability to climate impacts to their financial security and income stability. Therefore, enhancing their knowledge and employability would increase their efficacy, agency and sense of well-being over managing future climate change risks.

It is recommended that public institutions establish formal platforms such as national student councils and regional consultation committees for university students to participate in the debates and decisions on future environmental policies. The consultation of university students on environmental decision-making can help them feel empowered and in control of their future.

We suggest greater emphasis on reflective, interactive and action-oriented strategies in future collaborations amongst university students and other stakeholders such as the media, government, businesses and civil society. Youth-focused organizations and civic institutions should provide platforms for university students for designing and delivering community workshops and environmental education projects and events.

Public health researchers could undertake inter-disciplinary studies that assess, from a medical perspective, the physiological, mental, emotional and functional implications of climate challenges, and the ensuing threats to youth security, employment, and development prospects.

Medical institutions and practitioners should provide and regularly monitor access to youth-tailored health and well-being services including emotional and mental healthcare, and insurance and risks governance tools that adequately address future climate challenges that youth will be facing. Investment is also required in the medical/hospital infrastructure to strengthen capacities for managing potential future climate-induced disasters, particularly in developing countries.

\section{Acknowledgements}

The authors thank all participants, key informants, universities and organizations in the Netherlands who participated in this study; and Professor D. Tilbury for her inputs to this research.

\section{REFERENCES}

1. Davidson MD. Wrongful harm to future generations: the case of climate change. Environ Values. 2008;17(4):471-88.

2. Gardiner SM. A perfect moral storm: climate change, intergenerational ethics and the problem of moral corruption. Environ Values. 2006;15(3):397-413.

3. Jones RN. An environmental risk assessment/management framework for climate change impact assessments. Nat Hazards. 2001;23(2-3):197-230.

4. United Nations Framework Convention on Climate Change (UNFCCC). Youth participation in the UNFCCC negotiation process: The United Nations, young people, and climate change. UNFCCC; 2010.

5. McMichael AJ, Lindgren E. Climate change: present and future risks to health, and necessary responses. J Intern Med. 2011 Nov;270(5):401-13.

6. Fritze JG, Blashki GA, Burke S, Wiseman J. Hope, despair and transformation: climate change and the promotion of mental health and wellbeing. Int J Ment Health Syst. 2008 Sep 17;2(1):13.

7. Doherty TJ, Clayton S. The psychological impacts of global climate change. Am Psychol. 2011 May-Jun;66(4):265-76.

8. Markowitz EM. Is climate change an ethical issue? Examining young adults' beliefs about climate and morality. Clim Change. 2012;114(34):479-95.

9. Harris PG. World ethics and climate change: from international to global justice. Edinburgh: Edinburgh University Press; 2010.

10. Denzin N, Lincoln Y. The SAGE handbook of qualitative research. 4th ed. London: SAGE Publications; 2011.

11. Marshall C, Rossman G. Designing qualitative research. 5th ed. Thousand Oaks: SAGE Publications; 2011.

12. Filho WL. Climate change at universities: results of a world survey. In: Filho WL, editor. Universities and climate change: introducing climate change to university programmes. Berlin: Springer-Verlag; 2010. p. 1-21.

13. Wolf J, Moser S. Individual understandings, perceptions, and engagement with climate change: insights from in-depth studies across the world. WIREs Clim Change. 2011;2(4):547-69.

14. Norgaard KM. Living in denial: climate change, emotions, and everyday life. Massachusetts (US): MIT Press; 2011.

15. Maibach EW, Leiserowitz A, Roser-Renouf C, Mertz CK. Identifying like-minded audiences for global warming public engagement campaigns: an audience segmentation analysis and tool development. PLoS One. 2011 Mar 10;6(3):e17571.

16. Swim JP, Clayton S, Doherty T, Gifford R, Howard G, Reser J, et al. Psychology and global climate change: addressing a multi-faceted phenomenon and set of challenges. Washington, D.C.: American Psychological Association; 2009.

17. Kidner D. Depression and the natural world: towards a critical ecology of psychological distress. Int J Crit Psychol. 2007;(19):123-46.

18. Chadwick A. Exemplification and behavior change: college students' perceptions of climate change impacts. In: Annual meeting of the National Communication Association (NCA) 9th Annual Convention; 2008 Nov. 21-4; San Diego, California.

19. Feldman L, Nisbet MC, Leiserowitz A, Maibach E. The climate change generation? Survey analysis of the perceptions and beliefs of young Americans. Fairfax: George Mason University; 2010.

20. Arnold HE, Cohen FG, Warner A. Youth and environmental action: perspectives of young environmental leaders on their formative influences. J Environ Educ. 2009;40(3):27-36.

21. Shove E. Beyond the ABC: climate change policy and theories of social change. Environ Plann A. 2010;42(6):1273-85.

22. Tilbury D, Ryan A. Today becomes tomorrow: re-thinking business practice, education and learning in the context of sustainability. J Glob Respon. 2011;2(2):137-50.

23. Anand P, Hunter G, Smith R. Capabilities and well-being: evidence based on the Sen-Nussbaum approach to welfare. Soc Indic Res. 2005;74(1):955 .

\section{Conflict of Interest}

None declared 